\title{
Comparison of Clinical and Hemodynamic Effects of Isoflurane and Sevoflurane Anesthesia in Calves
}

\author{
Rahime Yaygingul', Ali Belge', lbrahim Akin', Cengiz Unsal' ${ }^{2}$, Osman Bulut ${ }^{1}$ \& Nuh Kilic'
}

\begin{abstract}
Background: Inhalation anesthesia is the preferred method for use on many animal species, including ruminants, due to its superiority over the injectable anesthetics. The most commonly used inhalation anesthetics are isoflurane and sevoflurane The aim of the study was to investigate the effects of isoflurane and sevoflurane anesthesia on the cardiovascular system of calves.

Materials, Methods \& Results: A total of 20 calves (11 male, 9 female) between 1 and 6 months in age and 50 to $85 \mathrm{~kg}$ in body weight were used. The calves were divided randomly into two groups of 10 each, with one group being administered isoflurane and the other sevoflurane. An intramuscular dosage of $0.1 \mathrm{mg} / \mathrm{kg}$ of xylazine was administered to the calves as premedication. Induction was performed $10 \mathrm{~min}$ after calves were given an intramuscular dosage of $4 \mathrm{mg} / \mathrm{kg}$ of ketamine. Inhalation anesthesia was maintained with isoflurane or sevoflurane in $100 \%$ oxygen saturation. Before anesthesia, after induction and at intervals of $5,10,15,20,25,30,45$, and $60 \mathrm{~min}$ of anesthesia, the body temperature, heart rate, and respiratory rate of the calves were recorded. Additionally, before anesthesia, after induction and at intervals of 15, 30, 45, and $60 \mathrm{~min}$ of anesthesia, serum electrolyte $\left(\mathrm{Na}^{+}, \mathrm{Ca}^{++}, \mathrm{K}^{+}, \mathrm{Mg}^{++}\right)$and blood gases $\left(\mathrm{pH}, \mathrm{pCO}_{2}, \mathrm{pO}_{2}, \mathrm{HCO}^{3-}, \mathrm{TCO}_{2}, \mathrm{O}_{2} \mathrm{Sat}\right.$, HCT) were evaluated from blood samples taken from both groups. The second derivation, durations and amplitudes of the $\mathrm{P}$ and T waves, the durations and amplitudes of the QRS complex, and the durations of PQ and QT intervals were evaluated on the ECGs recorded before anesthesia, after induction and during anesthesia. Following anesthesia termination, the extubation time and the time it took for straightening of the head and standing up were recorded. Decrease in heart rate and body temperature were found significant in two of the groups. Decrease in respiratory rate compared to initial values after premedication was statistically significant for both groups. However, during anesthesia, an increase occurred. This incresae in respiration rate was not statistically significant compared to initial values. The incease in the values of $\mathrm{pCO}_{2}, \mathrm{pO}_{2}, \mathrm{HCO}_{3}$ and the decrease in the values of $\mathrm{pH}$ and Hct comparing the initial values was found statistically significant in both groups. Discussion: In ruminants, isoflurane has an induction concentration of 3-5\% and an anesthetic concentration of 1.5-3\%, while sevoflurane has an induction concentration of $4-6 \%$ and an anesthetic concentration of $2.5-4 \%$. In this study, the concentration of isoflurane was $2.3 \%$ (2-5) and the of sevoflurane was $4.07 \%$ (3-5) for surgery. In the isoflurane group, extubation, straightening of the head and standing up times were $12.40 \pm 3.77 \mathrm{~min}, 20.4 \pm 1.57 \mathrm{~min}$, and $30.80 \pm 1.89$ min, respectively. In the sevoflurane group, extubation, straightening of the head and standing up times were $13.40 \pm 4.99$, $19.2 \pm 1.49$, and $28.0 \pm 1.83 \mathrm{~min}$, respectively. Although the calves in the isoflurane group were extubated earlier than those of the sevoflurane group, the time elapsed for straightening of the head and standing up were longer than that of the sevoflurane group. The anesthesia protocol provided a smooth anesthetic administration, general anesthesia and awakening. In conclusion, the effects of isoflurane and sevoflurane anesthesia on the cardiovascular and respiratory system were similar, and although the changes that emerged during anesthesia were statistically significant, it was nonetheless found that the changes were within the physiological limits.
\end{abstract}

Keywords: calves, isoflurane, sevoflurane, general anesthesia, hemodynamic effects.

${ }^{1}$ Departement of Surgery \& ${ }^{2}$ Department of Physiology, Faculty of Veterinary Medicine, University of Adnan Menderes, Aydin, Turkey. CORRESPONDENCE: R. Yaygıngül [ryaygingul@ hotmail.com - Fax: +90 (256) 2470720]. Department of Surgery, Faculty of Veterinary, Adnan Menderes University. Isikli. 09017 Aydin, Turkey. 
R. Yaygingul, A. Belge, I. Akin, et al. 2017. Comparison of Clinical and Hemodynamic Effects of Isoflurane and

\section{INTRODUCTION}

Inhalation anesthesia is the preferred method for use on many animal species, including ruminants, due to its superiority over the injectable anesthetics $[3,4,36]$. The most commonly used inhalation anesthetics are isoflurane and sevoflurane [28]. Isoflurane is a clear, colorless, stable liquid inhalation anesthetic. Induction of and recovery from isoflurane anesthesia are rapid due to the low blood/gas partition coefficient $[17,30]$. Sevoflurane is a colorless, liquid, nonirritant, nonflammable and nonexplosive volatile anesthetic agent with a slightly etheric odor. Induction of, recovery from and the control of intraoperative awareness of sevoflurane anesthesia is faster than isoflurane anesthesia, but its cost is quite high [17,30].

This aim of the present study was to investigate the effects of isoflurane and sevoflurane anesthesia on the cardiovascular system of calves.

\section{MATERIALS AND METHODS}

\section{Animals}

Twenty calves undergoing general anesthesia for variety of clinical reasons in Adnan Menderes University Veterinary Faculty Surgery Department were enrolled in the study A total of 20 calves (11 male, 9 female) between 1 and 6 months (isoflurane average $3.2 \pm 0.45$, sevoflurane average $2.55 \pm 0.39$ ) in age and 50 to $85 \mathrm{~kg}$ in body weight (isoflurane average $64.5 \pm$ 2.63 , sevoflurane average $64.30 \pm 2.80$ ) were used. The calves were divided randomly into two groups of 10 each, with one group being administered isoflurane and the other sevoflurane. The calves were premedicated with an intramuscular dosage of $0.1 \mathrm{mg} / \mathrm{kg}$ of xylazine $\left(\text { Alfazyne }^{\circledR}\right)^{1}$, and induction was performed $10 \mathrm{~min}$ later via an intramuscular dosage of $4 \mathrm{mg} / \mathrm{kg}$ ketamine $\left(\text { Alfamine }{ }^{\circledR}\right)^{1}$. Inhalation anesthesia was maintained with either isoflurane (Isoflurane $\left.{ }^{\circledR}\right)^{2}$ or sevoflurane $\left(\text { Sevorane Likit }{ }^{\circledR}\right)^{3}$ in $100 \%$ oxygen saturation.

Body temperature $\left(\mathrm{BT},{ }^{\circ} \mathrm{C}\right)$, heart rate (HR, beats per minute), and respiratory rate (RR, respiration per minute) were recorded before anesthesia, after induction and at intervals of 5, 10, 15, 20, 25, 30, 45, and $60 \mathrm{~min}$ of anesthesia.

Analysis

Serum electrolyte [sodium $\left(\mathrm{Na}^{++}\right)$, ionized calcium $\left(\mathrm{Ca}^{++}\right)$, potassium $\left(\mathrm{K}^{+}\right)$, magnesium $\left.\left(\mathrm{Mg}^{++}\right)\right]$and blood gases [arterial $\mathrm{pH}(\mathrm{pH})$, arterial carbon dioxide pressure $\left(\mathrm{pCO}_{2}\right)$, arterial oxygen pressure $\left(\mathrm{pO}_{2}\right)$, bicarbonate concentration $\left(\mathrm{HCO}^{3-}\right)$, total carbon dioxide $\left(\mathrm{TCO}_{2}\right)$, hematocrit $(\mathrm{HCT})$, and oxyhemoglobin saturation $\left.\left(\mathrm{O}_{2} \mathrm{Sat}\right)\right]$ were evaluated in the blood samples taken before and after induction and at intervals of 15, 30, 45, and $60 \mathrm{~min}$ of anesthesia. The second derivation, durations and amplitudes of the $\mathrm{P}$ and $\mathrm{T}$ waves, durations and amplitudes of the QRS complex, and durations of PQ and QT intervals were evaluated on the electrocardiography (ECG) recorded before anesthesia, after induction and during anesthesia. Following anesthesia termination, extubation time and the time it took for the straightening of the head and standing up were recorded.

\section{Statistical analysis}

The results were analyzed through descriptive statistics using the Statistical Package for Social Sciences (SPSS, IBM) 19.0. All data are presented as the arithmetic mean $(\bar{x})$ and the standard error of the mean $(\mathrm{S} \bar{x})$. Distribution and fitness of the data were evaluated by the Shapiro-Wilks test. Statistical tests were performed via two-way variance analysis in repeated measures, and multiple comparisons were corrected with the post-hoc Generalized Linear Model (GLM). Differences were considered statistically significant if $P<0.05$.

\section{RESULTS}

The animals were anesthetized and operated on for the treatment of their respective conditions, which included 12 cases of umbilical hernia, 6 cases of omphalitis and 2 cases of omphalophlebitis (Table 1). Physiological parameters, electrolyte analysis results, blood gas values and electrocardiography (ECG) results are shown in Tables 2, 3, and 4, respectively.

During operations, the mean concentration of isoflurane was $2.3 \%$ (1.5-3) and $4.07 \%$ (2-5) for sevoflurane. The average operation time was $66.10 \pm 5.13$ $\mathrm{min}$ in the isoflurane group and $65.20 \pm 9.35 \mathrm{~min}$ in the sevoflurane group. During the operations, 2 animals in the isoflurane group and 3 animals in the sevoflurane group urinated. Saliva, mucus, regurgitation, and defecation were not observed in either of the groups. Muscle relaxation was near normal in all groups.

Changes in the waves during anesthesia for the isoflurane and sevoflurane groups were not statistically significant $(P>0.05)$. Prior to anesthesia, there was no arrhythmia in any of the calves in the isoflurane group. During anesthesia, a second degree atrioventricular 
R. Yaygingul, A. Belge, I. Akin, et al. 2017. Comparison of Clinical and Hemodynamic Effects of Isoflurane and

(AV) block was observed in one calf. For this arrhythmia, no intervention with medication was made, as the heart rate was within the physiological limits during the surgery, and the patient was followed up closely. In the sevoflurane group, there was no arrhythmia according to the ECGs taken before and during anesthesia.

Table 1. Operation time, extubation time, head straightening, time to standing up of groups.

\begin{tabular}{ccc}
\hline Variable & Isoflurane group & Sevoflurane group \\
\hline Operation time $(\mathrm{min})$ & $66.10 \pm 5.13$ & $65.20 \pm 9.35$ \\
Extubation time $(\mathrm{min})$ & $12.40 \pm 3.77$ & $13.40 \pm 4.99$ \\
Head straightening $(\mathrm{min})$ & $20.4 \pm 1.57$ & $19.2 \pm 1.49$ \\
Time to standing up $(\mathrm{min})$ & $30.80 \pm 1.89$ & $28.0 \pm 1.83$ \\
\hline
\end{tabular}

Table 2. Effects of different anesthesia groups on body temperature, respiatory rate, heart rate over time.

\section{Isoflurane}

\section{Sevoflurane}

\begin{tabular}{|c|c|c|c|c|c|c|}
\hline $\begin{array}{l}\mathrm{N}=10 \\
\text { (for each } \\
\text { group) }\end{array}$ & $\begin{array}{c}\text { Body } \\
\text { Temperature }{ }^{\circ} \mathrm{C} \\
\bar{X}_{ \pm S} \bar{x}\end{array}$ & $\begin{array}{l}\text { Respiratory } \\
\text { Rate (respira- } \\
\text { tion per minute) } \\
\qquad \bar{X} \pm S \bar{x}\end{array}$ & $\begin{array}{c}\text { Heart Rate } \\
\text { (beats per } \\
\text { minute) } \\
\bar{X}_{ \pm S} \bar{x}\end{array}$ & $\begin{array}{l}\begin{array}{l}\text { Body Tem- } \\
\text { perature }{ }^{\circ} \mathrm{C}\end{array} \\
\bar{X} \pm \mathrm{S} \bar{x}\end{array}$ & $\begin{array}{l}\begin{array}{c}\text { Respiratory } \\
\text { Rate (respira- } \\
\text { tion per minute) } \\
\qquad \bar{X} \pm S \bar{x}\end{array}\end{array}$ & $\begin{array}{c}\text { Heart Rate } \\
\text { (beats per } \\
\text { minute) } \\
\bar{X}_{ \pm} \mathrm{S} \bar{x}\end{array}$ \\
\hline $\begin{array}{l}\text { Baseline } \\
\text { Value }\end{array}$ & $38.7 \pm 0.18$ & $42.20 \pm 5.43$ & $88.00 \pm 7.21$ & $38.5 \pm 0.21$ & $37.20 \pm 4.78$ & $94.00 \pm 6.39$ \\
\hline $\begin{array}{l}\text { Induction } \\
\text { after } \\
0 \text { min }\end{array}$ & $38.5 \pm 0.18$ & $52.20 \pm 4.30 *$ & $76.40 \pm 5.10^{*}$ & $38.44 \pm 0.24$ & $40.00 \pm 4.01$ & $77.80 \pm 4.71^{* *}$ \\
\hline $\begin{array}{c}\text { During } \\
\text { Anaesthesia } \\
5 \mathrm{~min}\end{array}$ & $38.3 \pm 0.17 * *$ & $49.40 \pm 4.05^{*}$ & $73.10 \pm 4.84 *$ & $38.3 \pm 0.24$ & $40.70 \pm 2.86$ & $72.80 \pm 4.62 * *$ \\
\hline $\begin{array}{c}\text { During } \\
\text { Anaesthesia } \\
10 \mathrm{~min}\end{array}$ & $38.2 \pm 0.22 * * *$ & $50.00 \pm 2.81^{* *}$ & $63.00 \pm 6.90 *$ & $38.1 \pm 0.23 * *$ & $41.10 \pm 2.10$ & $68.90 \pm 4.09^{* *}$ \\
\hline $\begin{array}{c}\text { During } \\
\text { Anaesthesia } \\
15 \mathrm{~min}\end{array}$ & $38.2 \pm 0.18 * * *$ & $49.70 \pm 2.54 * *$ & $69.70 \pm 4.52 *$ & $38.0 \pm 0.22 * *$ & $38.30 \pm 3.45$ & $68.80 \pm 4.74 * *$ \\
\hline $\begin{array}{c}\text { During } \\
\text { Anaesthesia } \\
20 \mathrm{~min}\end{array}$ & $38.1 \pm 0.23 * * *$ & $47.00 \pm 3.04^{*}$ & $69.80 \pm 3.92 *$ & $38.1 \pm 0.26^{* *}$ & $39.60 \pm 4.31$ & $69.30 \pm 3.80 * *$ \\
\hline $\begin{array}{c}\text { During } \\
\text { Anaesthesia } \\
25 \mathrm{~min}\end{array}$ & $38.0 \pm 0.21 * * *$ & $45.50 \pm 2.64$ & $72.80 \pm 4.30^{*}$ & $38.0 \pm 0.29 * *$ & $40.10 \pm 3.02$ & $67.60 \pm 4.19 * * *$ \\
\hline $\begin{array}{c}\text { During } \\
\text { Anaesthesia } \\
30 \mathrm{~min}\end{array}$ & $37.8 \pm 0.23 * * *$ & $44.90 \pm 3.07$ & $74.90 \pm 4.89$ & $38.0 \pm 0.21 * *$ & $40.10 \pm 2.70$ & $68.80 \pm 4.03^{* *}$ \\
\hline $\begin{array}{c}\text { During } \\
\text { Anaesthesia } \\
45 \mathrm{~min}\end{array}$ & $37.8 \pm 0.28 * * *$ & $42.40 \pm 3.38$ & $75.10 \pm 5.43$ & $37.9 \pm 0.27 * *$ & $40.40 \pm 2.83$ & $67.30 \pm 4.12^{* * *}$ \\
\hline $\begin{array}{c}\text { During } \\
\text { Anaesthesia } \\
60 \mathrm{~min}\end{array}$ & $37.7 \pm 0.30 * * *$ & $41.10 \pm 3.30$ & $75.10 \pm 4.79$ & $37.9 \pm 0.25^{* *}$ & $37.50 \pm 1.93$ & $68.00 \pm 3.67 * *$ \\
\hline
\end{tabular}




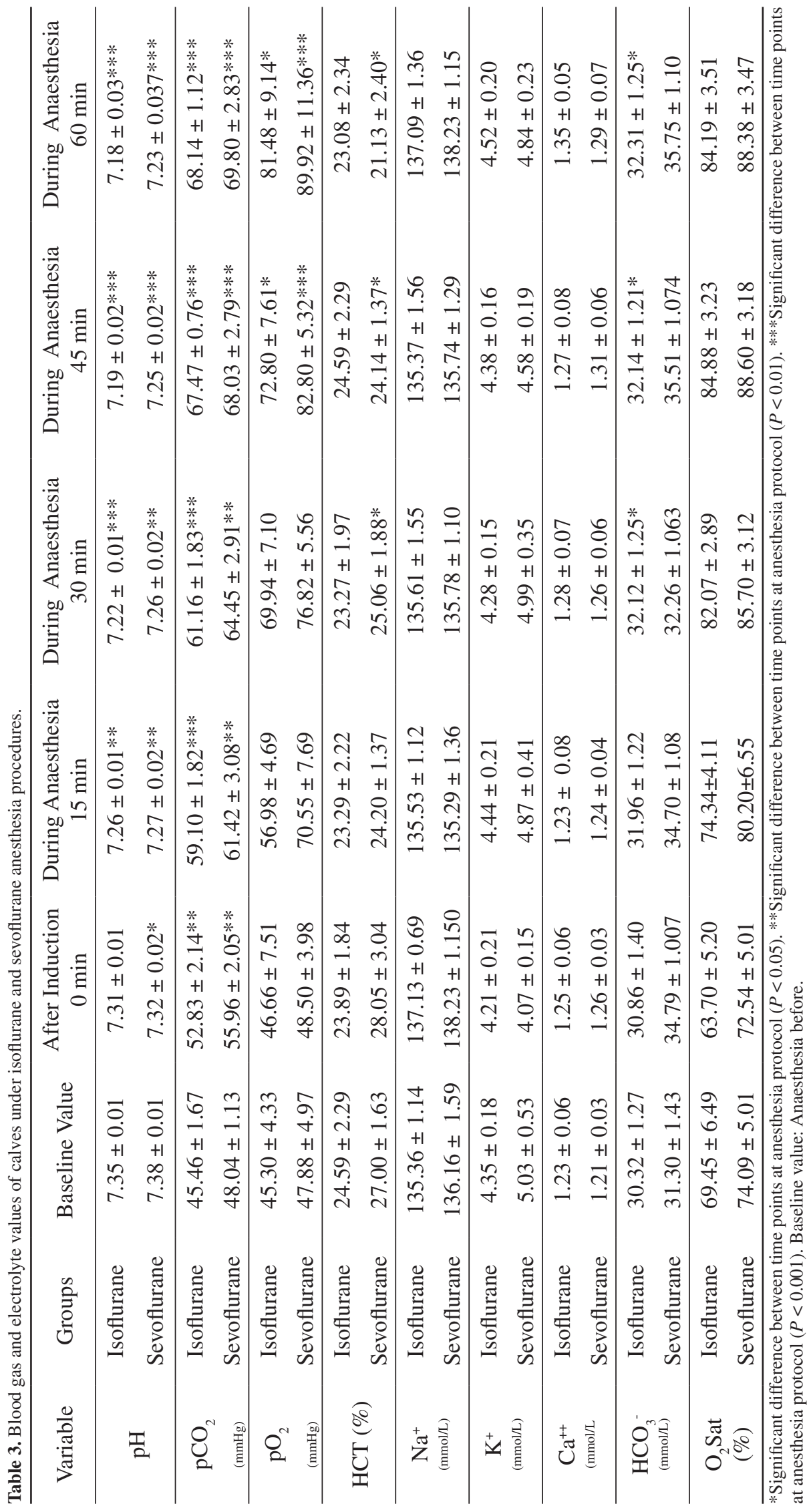




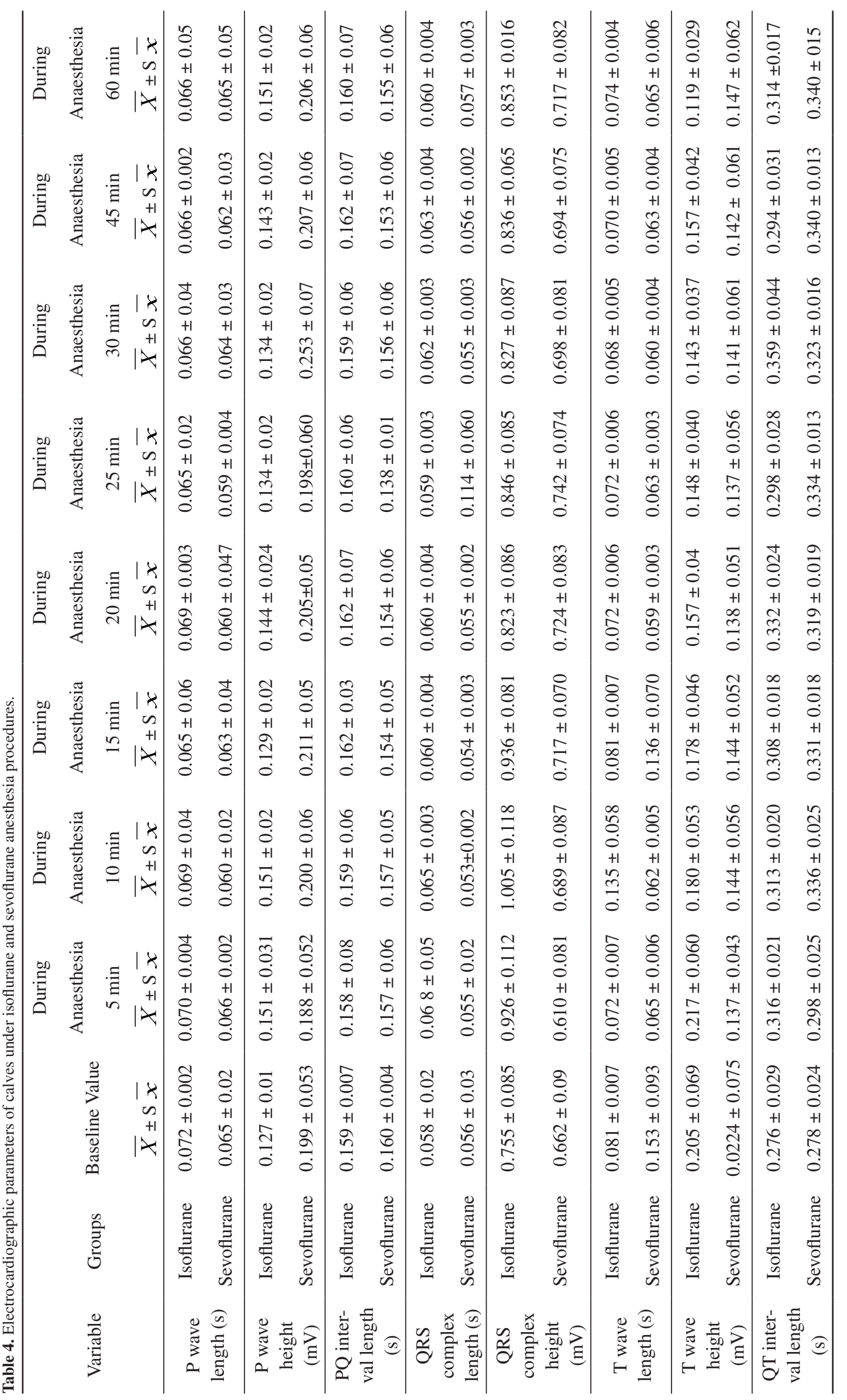


R. Yaygingul, A. Belge, I. Akin, et al. 2017. Comparison of Clinical and Hemodynamic Effects of Isoflurane and

\section{DISCUSSION}

Although it is inexpensive but operationally limited, inhalation anesthesia is a more preferred method to that of injectable anesthesia for small ruminants, especially those that are weak, pregnant, very young or older, and in operations that last longer than an hour or in complicated surgical applications. Other important advantages of inhalation anesthesia are its manageable anesthetic depth and fast awakening from it. This study aimed to investigate the effects of isoflurane and sevoflurane anesthesia on the cardiovascular system of calves.

In ruminants, isoflurane has an induction concentration of 3-5\% and an anesthetic concentration of $1.5-3 \%$ [7], while sevoflurane has an induction concentration of 4-6\% and an anesthetic concentration of 2.5$4 \%[14,31]$. In this study, the concentration of isoflurane was $2.3 \%$ (2-5) and that of sevoflurane was $4.07 \%$ (3-5) for surgery. The calves were premedicated with a $0.1 \mathrm{mg} / \mathrm{kg}$ intramuscular dosage of xylazine, induction was performed with a $4 \mathrm{mg} / \mathrm{kg}$ intramuscular dosage of ketamine, and orotracheal anesthesia was maintained with either isoflurane or sevoflurane inhalation. In the isoflurane group, extubation, straightening of the head and standing up times were $12.40 \pm 3.77 \mathrm{~min}, 20.4 \pm$ $1.57 \mathrm{~min}$, and $30.80 \pm 1.89 \mathrm{~min}$, respectively. In the sevoflurane group, extubation, straightening of the head and standing up times were $13.40 \pm 4.99,19.2 \pm$ 1.49 , and $28.0 \pm 1.83 \mathrm{~min}$, respectively. Although the calves in the isoflurane group were extubated earlier than those of the sevoflurane group, the time elapsed for straightening of the head and standing up were longer than that of the sevoflurane group. The anesthesia protocol provided a smooth anesthetic administration, general anesthesia and awakening.

Common complications during inhalation anesthesia in small ruminants include hypersalivation, regurgitation, tympani, apnea urination, defecation, and muscle tremors. In order to prevent these complications, it is recommended that animals be restricted from consuming food, $12-18 \mathrm{~h}$, and water, 2-6 h, before anesthesia [17,26,31]. In compliance with this recommendation, the animals in this study were prevented from food intake $12 \mathrm{~h}$ before and from water intake 6 $\mathrm{h}$ before anesthesia. During the operations, two animals in the isoflurane group and three animals in the sevoflurane group urinated. No other complications were encountered.
Some authors $[2,9,13,14,41]$ have reported that in many animal species, reduction in body temperature after inhalation anesthesia is due to impaired thermoregulation from inhibition of the limbic-hypothalamic center on account of the applied drugs and to the decrease of the metabolic activity and muscle activities of the organism resulting from deterioration of the hemostasis of the body heat. In the present study, a decrease in body temperature was observed, but these parameters remained within the normal limits for each group, despite the decrease being statistically significant in both groups. In particular, the decrease in the isoflurane group was significant from the 5th min of the anesthesia, compared to the baseline value, whereas it was significant from the 10th min of the anesthesia in the sevoflurane group. These findings were similar to previous studies, where body temperature was reported to decrease in buffalos [6], dogs [9], goats [22] and camels [2] after isoflurane anesthesia, and in dogs [9], cattle [14] and goats [22] after sevoflurane anesthesia. In the current study, regarding body temperature, there were no significant differences between isoflurane and sevoflurane anesthesia.

It has been reported that the effects of isoflurane and sevoflurane on the cardiovascular system are similar, and that depending on dosage, both anesthetics decrease arterial blood pressure, cardiac efficiency and systemic vascular resistance $[1,11,20,28,40]$. The effect of isoflurane anesthesia on heart rate has been stated to vary among different species of animals and according to age. For example, an increased heart rate has been reported in dogs [12], horses [39], bulls [15], and cattle [35], and a decreased heart rate in lambs [5], sheep [13], and pigs [32]. In dogs, the heart rate either rises or remains stable [38] by increasing the alveolar concentration in the inhalation anesthetic, or it drops by an increase in anesthetic depth due to increasing vagal tonus [17]. In the current study, the heart rate decreased in both the isoflurane and sevoflurane groups. This decrease was statistically significant at premedication, induction and at the 5th, 10th, 15th, and 20th min intervals of anesthesia in the isoflurane group $(P<0.05 ; P<0.01)$. In the sevoflurane group, the decrease in heart rate was statistically significant at premedication, induction and during anesthesia $(P<0.01 ; P<0.001)$. There was no statistically significant difference in heart rate between the two 
groups $(P>0.05)$. The heart rate remained within the normal limits for each group in all time periods. The concentration of the anesthetic gases released was kept constant during anesthesia, and the operation was performed while the animal was under surgical anesthesia. A decreased heart rate in the anesthetized animals was expected to be related with the increased depth of the isoflurane and sevoflurane anesthesia. When both groups were compared in terms of heart rate, there was no statistically significant difference, the results of which support the idea that the reduced number of heart beats was in fact caused by the depth of the anesthesia.

It has been reported that, like other inhalation anesthetics, sevoflurane and isoflurane cause dosagerelated respiratory depression in many animal species, and that the effects of the two anesthetic agents on the respiratory system are similar. As the dose increases, depression deepens in spontaneous ventilation $[9,21]$. Studies have reported that sevoflurane anesthesia induces respiratory depression in cattle [35], cats [21], and dogs [10], and that isoflurane induces respiratory depression in cattle [35] in a dose dependent manner. In the present study, the respiratory rate decreased after premedication and increased after induction and during anesthesia for both groups. This increase was statistically significant for the isoflurane group but not in the sevoflurane group. However, there was no statistical difference between the two groups. The findings obtained in this study differ from those reported by Hikasa et al. [21] and Doi et al. [10], where it was stated that the increase in respiratory rate was possibly caused by anesthesia or pain. In some steps of the operations, after the depth of anesthesia was changed, the respiratory rate was found to be normal. The difference between the findings from this study and those from the afore mentioned two studies could be attributed to an ineffective anesthetic level during operations. Furthermore, certain studies have emphasized that the increase in respiratory rate may be caused by the increase in the amount of $\mathrm{pCO}_{2}$ resulting from the induction of the central and peripheral chemoreceptors $[8,18,24,29,42]$.

Isoflurane has been reported to cause respiratory depression depending on dosage, and in the general anesthesia with spontaneous respiration, an increase in the amount of $\mathrm{CO}_{2}$ in the blood and a decrease in arterial $\mathrm{pH}$ occur $[8,18,24,29,42]$. In this study, the decrease in the $\mathrm{pH}$ level of the isoflurane group during administration of anesthesia at the 15th $(P<0.01), 30$ th $(P<0.001), 45$ th $(P<0.001)$, and 60th $(P<0.001)$ min compared to the baseline value was statistically significant. The decrease in the $\mathrm{pH}$ level of the sevoflurane group, after induction $(P<$ $0.05)$ and during administration of anesthesia at the 15th $(P<0.01), 30(P<0.01), 45$ th $(P<0.001)$ and 60th $(P<0.001)$ min compared to the baseline value was statistically significant. In the isoflurane group, $\mathrm{pCO}_{2}$ was determined to be $45.46 \pm 1.67$ at the beginning, $52.83 \pm 2.14$ after induction, $59.10 \pm 1.82$ at the 15th $\min , 61.16 \pm 1.83$ at the 30th $\min , 67.47 \pm 0.76$ at the 45 th $\mathrm{min}$, and $68.14 \pm 1.12$ at the 60 th $\mathrm{min}$. At these time points, the increase from the baseline value was statistically significant. In the sevoflurane group, $\mathrm{pCO}_{2}$ was determined to be $48.04 \pm 1.13$ at the beginning, $55.96 \pm 2.05$ after induction, $61.42 \pm$ 3.08 at the 15 th $\mathrm{min}, 64.45 \pm 2.91$ at the 30 th $\mathrm{min}$, $68.03 \pm 2.79$ at the 45 th $\mathrm{min}$, and $69.80 \pm 2.83$ at the 60 th $\mathrm{min}$. At these time points, the increase from the baseline value was statistically significant. However, there was no statistically significant difference in $\mathrm{pCO}_{2}$ levels between the two groups. Additionally, respiratory acidosis developed in both groups due to the increase of $\mathrm{pCO}_{2}$ value and decrease of $\mathrm{pH}$. These results showed similarity with the findings of Hikasa et al. [18]. The increase in the levels of $\mathrm{pCO}_{2}$ during isoflurane and sevoflurane anesthesia was reported to be higher in dogs [37] than in cats [19] and humans [10]. Schulze et al. [33], in their study, stated that the increase in $\mathrm{pCO}_{2}$ in animals under isoflurane anesthesia was associated with hypoventilation and pressure on the lungs during dorsal recumbency of the animal. In this study, the increase in $\mathrm{pCO}_{2}$ and the cause of respiratory acidosis were attributed to the animals'recumbent position.

The present study found that there was a decrease in the HCT values in the isoflurane and sevoflurane groups compared to baseline values. While this decrease was not statistically significant in the isoflurane group, it was statistically significant at the 30th $(P<0.05), 45$ th $(P<0.05)$ and 60th $(P<0.05)$ $\mathrm{min}$ in the sevoflurane group. However, there was no significant difference in HCT values between the two groups, and although the HCT values decreased, they were still within the physiological limits. The decrease in the HCT levels during anesthesia could have been 
R. Yaygingul, A. Belge, I. Akin, et al. 2017. Comparison of Clinical and Hemodynamic Effects of Isoflurane and

the result of fluid leaks from the capillary membranes or the effect of the sampling methods.

Changes in the $\mathrm{O}_{2} \mathrm{Sat}, \mathrm{Na}^{++}, \mathrm{Ca}^{++}$and $\mathrm{K}^{+}$levels in both the isoflurane and sevoflurane groups were not statistically significant compared to the baseline values, and there was no statistical difference between the groups. Similar findings have been reported in goats [18] and buffalos [6].

Preanesthetics and anesthetics may cause clinically different forms of arrhythmia due to the alterations in heart rate they precipitate $[23,34]$. Although these arrhythmias are able to be simply assessed by palpation of the heart beat auscultation or femoral pulse, electrocardiography is necessary for definitive diagnosis of arrhythmia and to determine the appropriate treatment. For this reason, it is important to include an ECG to the monitoring parameters in all patients under anesthesia. Normal sinus rhythm was detected in the ECGs of all the animals used in this study. Güzel and Perk [16] reported the formation of an atrioventricular junctional rhythm in one of the 24 patients taking isoflurane anesthesia. Similarly, in our study, a second degree AV block was formed on a calf in the isoflurane anesthesia group. In agreement with Miller et al. [25], who stated that intervention was not necessary so long as the arrhythmia did not progress, no intervention was made for the calf; however, it was closely followed, and after a short time, the rhythm returned to a normal level. On the other hand, in the sevoflurane group, no arrhythmia was observed in ECGs taken before and during anesthesia.

\section{CONCLUSIONS}

In conclusion, the effects of isoflurane and sevoflurane anesthesia on the cardiovascular and respiratory system were similar, and although the changes that emerged during anesthesia were statistically significant, it was nonetheless found that the changes were within the physiological limits. As the results showed there to be no statistical difference between the groups, both of the anesthetics can be safely used on calves. Though with that said, it is believed that isoflurane would be economically preferable to sevoflurane, as the latter is more expensive. In evaluating all these findings collectively, it can be concluded that using isoflurane is more advantageous for use on calves.

\section{MANUFACTURERS \\ ${ }^{1}$ Ege Vet Hayvancılık San. ve Tic. Ltd. Izmir, Turkey. \\ ${ }^{2}$ Adeka ilaç sanayi ve Ticaret A.Ş. Samsun, Turkey. \\ ${ }^{3}$ Abbott Laboratuarları ith. ihr. ve Tic. Lth. Istanbul, Turkey.}

Acknowledgements. The authors would like to acknowledge the assistance of the surgery departement staff and veterinary students of the University of Adnan Menderes in data collection and the Adnan Menderes University Scientific Research Foundation for financial support. The authors do not have potential conflicts of interest to declare.

Ethical approval. The ethical approval of the study was provided by the University's Institutional Animal Care and Use Committee (approval number: 2012/080). Each calve owner consented to the anesthetic procedure.

Declaration of interest. The authors report no conflicts of interest. The authors alone are responsible for the content and writing of paper.

\section{REFERENCES}

1 Aida H., Mizuna Y., Hobo S., Yoshida K. \& Fujinaga T. 1996. Cardiovascular and pulmonary effects of sevoflurane anesthesia in horses. Veterinary Surgery. 25: 164-170.

2 AL-Sobayll F., Ahmed A.F. \& El-Tookhy O. 2016. Evaluation of isoflurane anesthesia after xylazine/ketamine administration in dromedary camels. Turkish Journal of Veterinary Animal Sciences. 40: 1-8.

3 Apaydın N Koç B. 2005. Köpeklerde Isoflurane ve Sevoflurane Anestezisinin Hemodinamik ve Biyokimyasal Parametrelere Olan Etkilerinin Karşılaştııılması, Veteriner Cerrahi Dergisi. 11: 31-35.

4 Bednarski R.M. \& Muir III W.W. 1991. Closed system delivery of halothane and isoflurane with a vaporize in the anesthetics circle. Veterinary Surgery. 20 (5): 353-356.

5 Brett C.M., Teitel D.F., Heymann M.A. \& Rudolph A.M. 1987. The cardiovascular effects of isoflurane in lambs. Anesthesiology. 67: 60-65.

6 Bold D., Singh K., Gopinathan A., Mohindroo J. \& Saini N.S. 2014. Comparative evaluation of halothane and isoflurane maintenance anesthesia in water buffaloes. Journal of Applied Animal Research. 42(3): 269-277.

7 Cantalapiedra A.G., Villanueva B. \& Pereira J.L. 2000. Anaesthetic potency of isoflurane in cattle: Determination of the minimum alveolar concentration. Veterinary Anaesthesia and Analgesia. 27(1): 22-26. 
R. Yaygingul, A. Belge, I. Akin, et al. 2017. Comparison of Clinical and Hemodynamic Effects of Isoflurane and

8 Crystal G.J., Zhou X., Gurevicius J., Czinn E.A., Salem M.R., Alam S., Piotrowski A. \& Hu G. 2000. Direct coronary vasomotor effects of sevoflurane and desflurane in in situ canine hearts. Anesthesiology. 292: 1103-1113.

9 Çeçen G., Topal A., Görgül O.S. \& Akgöz S. 2009. The cardiopulmonary effects of sevoflurane, isoflurane and halothane anesthesia during spontaneous or controlled ventilation in dogs. Veterinary Journal of Ankara University. 56: 255-261.

10 Doi M., Katoh T., Takii T., Yura M. \& Ikeda K. 1987. The respiratory effects of sevoflurane in dogs. Masui. 36: 1053-1057.

11 Ebert T.J., Harkin C.P. \& Muzi M. 1995. Cardiovascular responses to sevoflurane: A review. Veterinary Anaesthesia Analgesia. 81: 11-22.

12 Frink E.J., Morgan S.E., Coetzee A., Conzen P.F. \& Brown B.R. 1992. The effects of sevoflurane, halothane, enflurane and isoflurane on hepatic blood flow and oxygenation in chronically instrumented grey hound dogs. Anesthesiology. 76: 85-90.

13 Gençcelep M., Atasoy N. \& Tas A. 2004. The effects of inhalation anaesthetics (halothane and isoflurane) on certain clinical and haematological parameters of sheep. Small Ruminant Research. 53: 157-160.

14 Greene S.A., Keegan R.D., Valdez R.A. \& Knowles D.K. 2002. Cardiovascular effects of sevoflurane in Holstein calves. Veterinary Anaesthesia Analgesia. 29: 59-63.

15 Greene S.A., Tyner C.L., Morris D.L. \& Hartsfield S.M. 1998. Comparison of cardiopulmonary effects of isoflurane and halothane after atropine-guaifenesine-thiamylal anaesthesia for rumenotomy in steers. American Journal of Veterinary Research. 49(11): 1891-1893.

16 Güzel Ö. \& Perk E.C. 2001. Diagnosis and treatment of cardiac rhythm disorders encountered during the general anaesthesia procedure and intraoperative period in dogs. Journal of the faculty of Veterinary Medicine Istanbul Univarsity. 28(2): 381-401.

17 Hall L.W., Clarke K.W. \& Trim C.M. 2001. Principle of sedation, analgesia and premedication in veterinary anaesthesia. In: Veterinary Anaesthesia. 10th edn. London: WB Saunders, pp.75-112.

18 Hikasa Y., Hokushini S., Takase K. \& Ogasawara S. 2002. Cardiopulmonary, haematological, 12 serum biochemical and behavioural effects of sevoflurane compared with isoflurane or 13 halothane in spontaneously ventilating goats. Small Ruminant Research. 43: 167-178.

19 Hikasa Y., Kawanabe H., Takase K. \& Ogasawara S. 1996. Comparisons of sevoflurane, isoflurane and Halothane anesthesia in spontaneously breathing cats. Veterinary Surgery. 25: 234-243.

20 Hikasa Y., Okuyama K., Kakuta T., Takase K. \& Ogasawara S. 1998. Anesthetic potency and cardiopulmonary effects of sevoflurane in goats: comparison with isoflurane and halothane. Canadian Journal of Veterinary Research. 62(4): 299-306.

21 Hikasa Y., Ohe N., Takase K. \& Ogasawara S. 1997. Cardiopulmonary effects of sevoflurane in cats: comparison with isoflurane, halothane and enflurane. Research in Veterinary Science. 63: 205-210.

22 Kumandaş A. \& Elma E. 2015. Comparison of sevoflurane and isoflurane effects on cardiovascular and respiratory system during spontaneous ventilation in Angora goats. Turkish Journal of Veterinary Animal Sciences. 39: 501-506.

23 Kushner L.I. \& Calvert A.C. 2000. Preanesthetic arrhythmias. Compendium on Continuing Education for the Practicing Veterinarian. 22: 61-73.

24 Meissner A., Weber T.P., Van Aken H., Zbieranek K. \& Rolf N. 2000. Recovery from myocardial stunning is faster with desflurane compared with propofol in chronically instrumented dogs. Veterinary Anaesthesia Analgesia. 91: 13331338 .

25 Miller M.S., Tilley L.P. \& Smith F.W.K. 1994. Disorders of cardiac rhythm. In: Brichard S.J. \& Sherding R.G. (Eds). Saunders Manual of Small Animal Practice. Philadephia: WB Saunders, pp.421-435.

26 Muir W.W. 2007. Considerations for general anesthesia. In: Thurmon J.C. Tranquilli W.J. \& Grimm K.A. (Eds). Lumb Jones Veterinary Anesthesia and Analgesia. 4th edn. Ames: Blackwell, pp.7-30.

27 Mutoh T., Kanamura A., Suzuki H., Tsubone H., Nishımura R. \& Sasaki N. 2001. Respiratory Reflexes in spontaneously breathing anesthetized dogs in response to nasal adminitration of sevoflurane, isoflurane or halotane. American Journal of Veterinary Research. 62(3): 311-319.

28 Mutoh T., Nishimura R., Kim H.Y., Matsunaga S. \& Sasaki N. 1997. Cardiopulmonary effects of sevoflurane, compared with halothane, enflurane, and isoflurane, in dogs. American Journal of Veterinary Research. 58(8): 885-890. 
R. Yaygingul, A. Belge, I. Akin, et al. 2017. Comparison of Clinical and Hemodynamic Effects of Isoflurane and

29 Pagel P.S., Kampine J.P., Schmeling W.T. \& Warltier D.C. 1991. Comparison of the systemic and coronary hemodynamic actions of desflurane, isoflurane, halothane, and enflurane in the chronically instrumented dog. Anesthesiology. 74(3): 539-551.

30 Pamuk K. 2003. Köpeklerde Halotan ve izofloran anestezisinin intraoküler basınca etkisinin karsılaştırılması. 70p. Doktora tezi (Sağlık Bilimleri Enstitüsü), Ankara Üniversitesi, Türkiye.

31 Reibold T.W. 2015. Ruminants. In: Grimm KA, Lamont LA, Tranquilli WJ, Greene S.A. \& Robertson S.A. (Eds). Lumb Jones Veterinary Anesthesia and Analgesia. 5th edn. Ames: Blackwell, pp.912-927.

32 Schieber R.A., Namnoum A., Sudgen A., Shio G.K., Orr R.A. \& Cook D.R. 1986. Haemodynamic effects of isoflurane in the new born piglet: comparison with halothane. Veterinary Anaesthesia Analgesia. 65(6): 633-638.

33 Schulze I., Poos E.M., Meyer H., List A.K., Kaestner S.B.R. \& Rhege J. 2016. Effects of preoperative carprofen on cardio-respiratory, hormonal and metabolic stress response in calves during umbilical surgery under isoflurane inhalation anaesthesia. The Veterinary Journal. 216: 18-24

34 Seeler D.C., Dodman N.H., Norman W.M. \& Court M.H. 1987. İntraoperativ cardiac dysrhythmias and their treatment. British Veterinary Journal. 143: 97-111.

35 Sellers G., Lin H.C., Chamorro M.F. \& Walz P.H. 2013. Comparison of isoflurane and sevoflurane anesthesia in holstein calves for placement of portal and jugular vein cannulus. American Journal of Animal Veterinary Science. 8(1): $1-7$.

36 Skarda R.T., Bednarski R.M., Muir W.W. \& Hubbell J.A.E. 1995. Inhalation Anesthesia. Handbook of Veterinary Anesthesia. Philadelphia: WB Saunders, pp.133-141.

37 Steffey E.P. \& Howland D. 1977. Isoflurane potency in the dog and cat. American Journal of Veterinary Research. 38: $1833-1836$.

38 Steffey E.P. \& Howland D. 1979. Halothane anaesthesia in calves. American Journal of Veterinary Research. 40: 372-376.

39 Steffey E.P., Kelly A.B. \& Woliner M.J. 1987. Time- related responses of spontaneously breathing, laterally recumbent horses to prolonged anaesthesia with halothane. American Journal of Veterinary Research. 48: 1646-1648.

40 Steffey P.E. \& Mama K.R. 2007. Inhalation anesthetics. In: Thurmon J.C. Tranquilli W.J. \& Grimm K.A. (Eds). Lumb Jones Veterinary Anesthesia and Analgesia. 4th edn. Ames: Blackwell, pp.355-93.

41 Topal A. 2005. Veteriner Anestezi. Bursa: Nobel \& Güneş, pp.107-128.

42 Vessal N., Spadavecchia C., Steiner A., Kirscher F. \& Levionnois O.L. 2011. Evaluation of the isoflurane-sparing effects of lidocaine infusion during umbilical surgery in calves. Veterinary Anaestesia and Analgesia. 38: 451-460. 